\title{
Construction of a Teaching Mode Combining WeChat Platform with Practical Training Classroom Under the OBE concept
}

\author{
MeiLing Duan ${ }^{1}$, YuQin Zhong ${ }^{1}$, WenRui Min ${ }^{1}$, Lin Zhu ${ }^{2}$, QinZheng Hou ${ }^{1, *}$, ZiJun \\ Huang ${ }^{3}$
}

${ }^{I}$ College of Life Sciences, Northwest Normal University, Anning, Lanzhou, Gunsu, China

${ }^{2}$ Heze City Mudan Disttrict Experimental Primary School, Heze, Shandong China

${ }^{3}$ Kunming Guandu District Vocational Senior High School, Guandu, Kunming, Yunnan China

*Corresponding author.Email: hou_qzh@nwnu.edu.cn

\begin{abstract}
Secondary school training courses affect students' technical skills and career plans, but students have a single way of acquiring resources and quality educational resources are not reasonably used. Students faces serious challenges and student can't adapt well to the demand for skilled talent in the job. Through the trial of "Internet + training class", the Outcome-based educational concept was integrated into the training education. With the WeChat platform as a carrier and product output as an orientation, student-centric organizations and supported education allow students to truly learn knowledge and achieve step-by-step results in the course of hands-on practice. The above measures also help students become more interested in learning, develop a sense of learning, and acquire practical skills for future employment.
\end{abstract}

Keywords: OBE concept, WeChat platform, training classroom, teaching mode.

\section{STATEMENT OF PROBLEM}

The development of training courses in secondary schools is very important for the training of students' technical skills, while it can guide the students' career planning and development. However, due to the characteristics of school-company cooperation from one major to one company, the quality educational resources around the school are not reasonably used for student technical skills training and career development and planning. Second, students have a single way to acquire resources, their ability to select learning resources is limited, and they cannot be used successfully. The above problems lead to a weak awareness of students' selfsolving problems and a decrease in their ability to innovate. Due to limited classroom time and complex tasks, lessons are primarily based on teacher demonstrations and post-imitation students, lacking a deep understanding of knowledge and the development of students' independent thinking abilities. At the same time, educational assessment relies on teacher assessment and does not pay sufficient attention to the development of students' abilities. For a long time, it has failed to adapt well to the demand for skilled talent in the employment. Students' development faces serious challenges.

The Directorate-general of the Education Ministry announced the "Points of Education Informatization Work in 2017" and pointed out that it is necessary to build a vocational education resource bank and promote the formation of a sustainable development model for open sharing of education[1]. Through the establishment and improvement of quality online learning resources open to working people, we continue to promote learning and lifelong learning for all. In the 2019 National Vocational Education Reform Implementation Plan, "Adapting to the development needs of" Internet + Vocational Education ", improving teaching methods using the latest information technology, and building online learning spaces such as virtual We also propose to promote universal application. "With the advent of the new technological revolution and the era of industrial transformation, the Internet has had a major impact on human production, life and learning [2]. Teachers integrate micro-information and fast-paced resources into teaching. Its novel and unique teaching mode is basically in line with the current learning methods of secondary 
vocational school students. The 14th Five-Year Plan outlines that vocational and technical education needs to explore an apprenticeship system with Chinese characteristics. We need to move forward from the national situation and understand the "three relationships" between vocational education and industry needs, education content and professional standards. Education and production process. At the same time, the various educational resources provided by information technology support the development of secondary vocational education to higher levels.

Incorporating the concept of Outcome-Based Education into hands-on training, it is a product-oriented student-centered organization and supported education, where students truly learn knowledge in the process of hands-on practice and produce step-by-step results. They can get it and increase the interest in learning. Learn the sense of gain and acquire practical skills that match future employment. Second, secondary vocational education is clearly specialized, and traditional teacher "full classroom" teaching methods reduce student learning efficiency. It employs teaching methods that allow secondary vocational educators to change the way they think about education and motivate learners to learn, make classroom education life-oriented, integrate educational strategies, and create educational objects. Must be personalized. This enables student learning initiatives, teacher-student interactions, and effective teaching methods. Diverse teaching methods goals [3]. Based on this, the latest information technology can be combined with it to overcome time and geographic constraints and facilitate individual learning for students. At the same time, the WeChat platform as a load body of information has diverse characteristics of graphic information, allowing students to learn anytime, anywhere and use fragmented time to achieve their own learning goals. With this as an aid, there is practical significance in reforming the traditional secondary vocational curriculum education mode.

\section{RESEARCH STATUS}

\subsection{Research status of OBE education concept}

Outcome-based education, also known as goaloriented and ability-oriented education [4]. Foreign research on OBE, which began in the 1980s, is rich in content and diverse in perspective. Some researchers and educational institutions have explained the definition of OBE from a general perspective [5]. Some researchers have suggested ways to apply the concept of OBE to education and have extensive experience in this regard. From a practical perspective, Acharya has proposed a performance-oriented OBE education and educational model that covers four elements: definition of learning outcomes, realization of learning outcomes, evaluation of learning outcomes, and use of learning outcomes. The four elements come together to form "from resultoriented", Educational model of "definition of learning outcomes, achievement of learning outcomes, and evaluation of learning outcomes" [6]. Currently, most students are confused about their career plans due to problems in setting up and teaching agricultural and forestry courses at vocational schools. The concept of OBE education can be used in secondary vocational classrooms to continually reform courses and classroom education. Modern Social and Occupational Resources This provides reference and support for introducing the OBE educational concept into the educational reform of specialized courses in agriculture and forestry.

Domestically, he theoretically summarized the concept of OBE education, proposed reforms and innovations in human resource development models based on the concept of OBE, and at the same time mentioned reforms in the school's application-oriented curriculum. The content of practical application is also beginning to attract attention. For the past decade, OBE's educational philosophy has attempted to apply to educational reforms in multiple applied courses. In 2014, Li Zhiyi was the first in the Ministry of Education to propose the concept of OBE, raising the concept of OBE from the theoretical research level to the practical research level in order to promote educational reform [7]. Since then, practical research under the guidance of the OBE concept has been actively developed, and Tsinghua University has restructured the general curriculum content and education evaluation system with a studentcentered ability-oriented approach[8].With the continuous deepening of research, the direction of biological agriculture and forestry is also continuously sought for curriculum design, and practical reform of OBE education concepts such as "food microbiology" and "gardening nursery science" continues [9]. Has been done A result-oriented curriculum education reform was attempted. Gradually develop the perfect research path, from human resource development requirements, reform of curriculum education implementation to evaluation of learning outcomes. Research on educational theory based on the OBE concept, research on educational practice, evaluation model of learning outcomes, educational quality standard system, human resource development plan, research on educational teams, etc. Laid the foundation for our future course education and research.

\subsection{Application of WeChat Public Platform in Education of Secondary Vocational Courses}

With the introduction of "Internet + " education, online education has once again become a boom [10]. Online education was first proposed as online learning for businesses to accommodate the training hours of different employees. With the integration of "Internet + " and education, "cloud classrooms" based on the mobile education platform have become a new trend in education 
development. The advent of online mobile education platforms can meet students' desire to learn the right way anytime, anywhere and facilitate the development of personalized talent training and information-based education. As a payload of modern information technology, the WeChat public platform has facilitated the development of modernization of education to some extent.

Since the 1980s, with the reform and opening up of Chian's economy and society, vocational pedagogy has also entered a period of rapid development, and has entered the stage of in-depth research on the development of educational implications. In particular, in 2010, the "National Medium- to Long-Term Education Reform and Development Plan Outline (2010-2020)" was published, raising interest in vocational education and emerging related policies [11]. The difference between vocational, technical and general education prevents traditional cognitive-oriented subject curriculum models from meeting the quality requirements of technical and skilled talents advocated by economic, social and technological development. Vocational education curriculum model, which has been forced to undergo continuous reform. By combining the concept of OBE with online courses in the "Internet +" era, Bai Jing builds a three-level open course structure model for learners, resources and information, and learning outcomes, and implements online course development [12]. After analyzing the current quality of education of secondary colleges, Zhou Jingkyo learned that secondary colleges could keep up with the pace of social development in the face of ever-changing social changes and made rational adjustments to modernization [13]. Researchers continue to try to bring the latest educational information technology into course education. Today, the WeChat public platform is gradually being used in course education to make up for the shortcomings of traditional classroom education. For example, given characteristics such as short lesson time, complex content, trivial knowledge points, and poor logic, it is difficult for regular classroom instruction to cover all aspects and detailed explanations. Teachers refine their teaching points and the WeChat public platform pushes courses to students and uses the data analysis capabilities of the WeChat public platform to assess learning effectiveness. At the same time, it communicates with students in the background to support their learning [14]. Second, Zhang Dawei proposed the establishment and practice of a three-step hybrid experimental teaching model based on the WeChat public platform in the background of several hours of class time [15]. Through these reforms, students will strengthen their dominant position in learning, foster awareness of collaborative innovation, enrich experimental educational resources, enhance interactivity in educational information, and at the same time improve the quality of course education. However, the development and application of an online education resource platform based on the OBE concept has little involvement in secondary vocational education. The development of the WeChat Public Platform Education Resource Library based on the OBE concept can solve the education problems of agriculture and forestry courses. The development of professional development skills also provides a practical basis for research on the integration of industry and education in modern apprenticeships with Chinese characteristics.

\section{GUIDANCE ON MODEL BUILDING}

\subsection{WeChat Platform Education Resource Development}

\subsubsection{Functional analysis}

Rich information: The establishment of an information platform enables multi-level interactions and experience exchanges to enhance the learning experience and enrich the content. In mobile learning, WeChat's multidimensional communication method and convenient and efficient communication platform can not only send photos, voices, videos, also share photos, videos and URLs to Students [16]. The above can facilitate convenient and rapid exchange and collaborative learning between teachers and students, and between students and students.

Subscription Push: After a user follows an official WeChat account, WeChat actively pushes information to users who subscribe to their WeChat account. However, the WeChat platform has certain restrictions on the information that is pushed daily, and teachers must carefully design course information and learning content to achieve comprehensive content and complete structure.

Conversation is search: This is a service method that automatically responds to responses. In the learning process, after the learner enters certain keywords, the public platform automatically responds to the questions that the learner encounters in time during the learning process. For ease of learner access, the platforms allow content to be created and summarized and categorized according to student learning and course characteristics.

\subsection{2. design principles}

Pay attention to the navigation bar: The navigation bar should be simple and clear, emphasizing knowledge topics and presenting the most comprehensive resource interactive navigation within a limited page. In addition, the resource design process provides timely feedback and effective help to help students quickly resolve issues encountered during the training process.

Fragmented learning support: Mobile learners are susceptible to external influences, unable to focus their 
attention for long periods of time, so that they can perform fragmented learning in "fragmented" time [17]. Therefore, the design of learning resources must follow the principle of fragmentation. The teacher divides the learning content and divides the complete knowledge into pieces of knowledge with a logical structure. Allows learners to use fragmented time to learn and master relatively complete knowledge structures.

Task-driven learning mode: The theory of situational awareness believes that in order for learning to be effective, it must be done in a particular social background and in meaningful situations [18]. When designing learning resources, follow a task-driven learning scenario model. This can stimulate and nurture learners' interest in learning.

\subsection{3. design process}

Interviews with professional teachers and students in secondary vocational training courses to understand the educational requirements of secondary schools, such as classroom education, collection and use of internet resources, and student learning behavior. And explore the flower resources at the Dounan Flower Market.

Combining Internet and corporate resources with secondary vocational education resources to develop a WeChat public platform education resource library suitable for secondary vocational school students' learning. Includes sharing enterprise flower resources, an introduction to flower characteristics, examples of great flower art production, and other graphic, audio, and video resources.

Use WeChat public platform resources to assist and perform follow-up education work. At the end of the class, teachers present their work to the WeChat public platform and use questionnaires to understand their learning traits and knowledge, skills, and emotional attitudes. Among them, the skill test is mainly used based on the skill operation score in the training classroom.

The concept of OBE is implemented through overall model building, definition of learning outcomes by corporate resources and development needs, achievement of learning outcomes by supportive education, evaluation of learning outcomes by student learning, and use of continuously revised learning outcomes. (Figure 1)

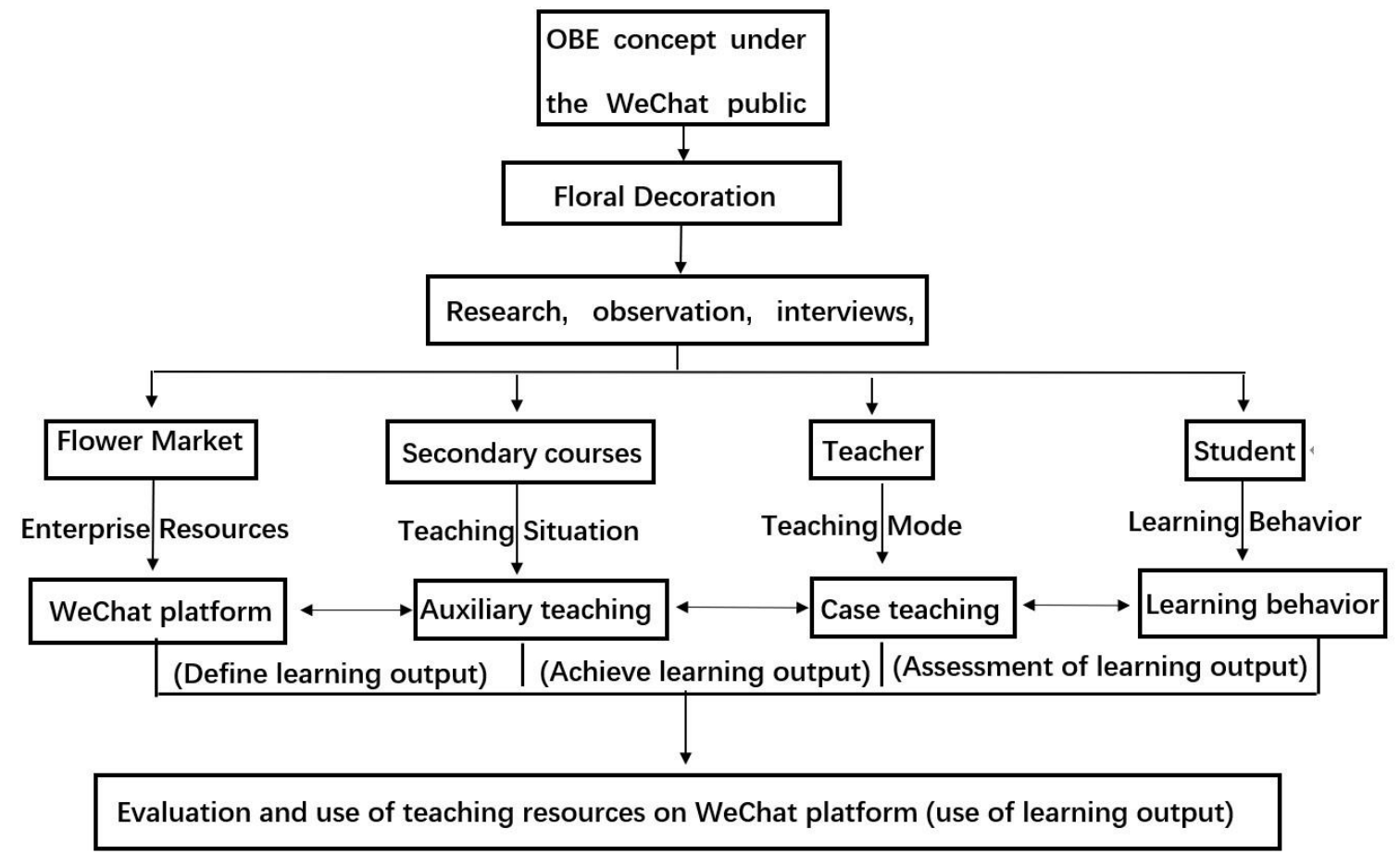

Figure 1 The construction model of WeChat platform teaching resources under the OBE concept

\subsection{Educational activities and resource design}

\subsection{1. teaching process design}

Curriculum educational activities are designed based on two subjects, three stages, and four goals. Starting with two major organizations, teachers and students, after analyzing the practical skills that students need to acquire based on training-based requirements, teachers organize and analyze them and present them to the WeChat public platform. Curriculum activities are divided into three stages: pre-class, in-class, and post-class, and students are required to complete four learning tasks: data collection, hands-on training, self-study, and group collaboration. 
Prior to class, teachers upload educational resources to the platform, and students use the information pushed by the WeChat public platform according to the course's task list to autonomously understand the educational goals and important and difficult points of new content. Collect and complete. Sharing audiovisual learning materials encourages students to use Information Learn to gain a foundation for corresponding skill demands and lay the foundation for the development of classroom education. In class, students share and interact as a major part of the classroom learning process. Teachers face-toface with students to explain, manipulate, and answer questions, and students complete classroom learning tasks through self-manipulation and practice. After class, teachers use the WeChat public platform to publish the results of their training operations and organize student votes. At the same time, we publish operational videos that help students identify and fill vacant seats and solve individual student learning problems in a timely manner. At the same time, teacher organize students to actively discuss and participate in resource sharing. Course education activities must achieve four goals: Depending on the needs of the company, teachers define learning outcomes, achieve learning outcomes with pre-class search and in-class education, and evaluate learning outcomes through platform voting and resource sharing capabilities. Finally, after organizing through analysis, students use the learning output.

\subsection{2. learning resource development and design}

Learning resources include training bases, work requirements, books and materials, and online learning resources. Teachers understand training-based skill requirements for secondary profession students to define educational goals, specific practical skills, and educational resources including teacher handouts and the book "Flower Decoration Techniques". Online learning resources are based on the WeChat public platform. Teachers design and develop texts, images, and audiovisual materials based on learning goals and activities.

\subsection{3. teaching evaluation}

Teachers break the single teaching method of the past and evaluate students' learning attitudes, group collaboration skills, and performance of their activities on the WeChat public platform. Student training results are displayed via the WeChat platform, and voting features can be used to achieve mutual student and teacher evaluation. This is a process assessment and the score accounts for $40 \%$ of the total course assessment score. Curriculum evaluation is the evaluation of students' proficiency in learning through the results of flower practice. The content of the survey is mainly designed based on five levels of knowledge, understanding, application, analysis and integration, which make up 60\% of the total. At the end of the course, teachers use questionnaires to understand students' learning conditions and learning interests and collect educational feedback.

\subsection{WeChat Platform Auxiliary Education Case Study Under the OBE Concept}

Teachers set up WeChat platforms, Baihuayuan and Sanwei studing room, based on the results of an enterprise resource survey. Different modules have different content, allowing students to integrate and improve through aggressive search.

\subsubsection{Import class}

Class import are primarily based on students displaying and reporting the results of their sorts, while at the same time students asking each other questions. According to the pre-class task list distributed by the teacher, students search for the required resources on the flower resource platform and classify the basic flower characteristics such as morphological characteristics, plant culture, conservation processing, application type, etc. To summarize (Figure. 2). And at the end of the course, teachers and students work together to answer questions before class.

\subsection{2. learning activities}

Educational activities are displayed in flower patterns, teachers explain the points, and students perform practical operations. Unlike previous education, this education initiative is in the hands of students, and teachers are just guides. Therefore, teachers can help solve teaching problems in time, and students can think independently and constantly try to innovate while learning basic skills. Then students can use the platform's Flower Classroom module to learn a variety of flower awakening procedures and maintenance methods (Figure 3). The video format also can attract students more, develop practical skills, and achieve their fragmented learning goals.

\subsection{3. assessment and evaluation}

The teacher showed the student's flower work on the WeChat platform. First, it can foster the joy of learning, and second, it can promote healthy competition among students. Visualizing teaching results also helps students self-assess and interact and communicate between teachers and students. This is another good idea for effective communication between home and school. Parents can use their mobile phones to understand their child's learning situation at school and at the same time vote for their child's progress. 


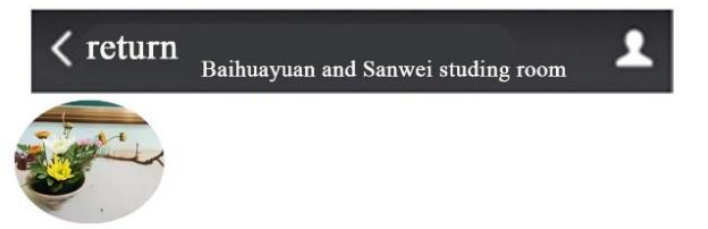

\section{Hydrangea macrophylla}

August 15, 2021
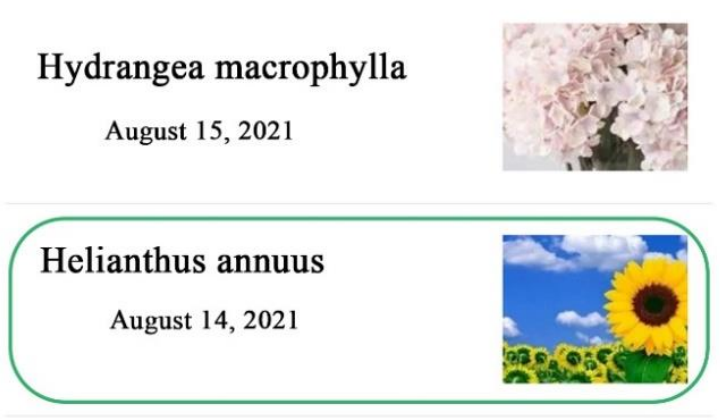

\section{Helichrysum bracteatum}

August 13, 2021

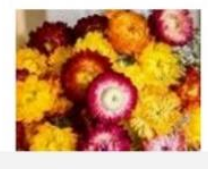

III) Flower Resources $\equiv \begin{gathered}\text { Flower } \\ \text { Classroom }\end{gathered} \quad \begin{gathered}\text { Flower Work } \\ \text { Exhibition }\end{gathered}$

$\times$

\section{Morphological features}

The sunflower was named because the inflorescences rotate with the sun.

It is an annual herb with upright stems, round and angular, hard and white,

and thick bristles.

\section{Plant culture}

Flower language: faith, brilliance, arrogance, loyalty, praise;

There is no one in the eyes, you are everywhere.

\section{Application}

Bouquet

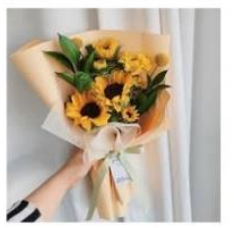

vase

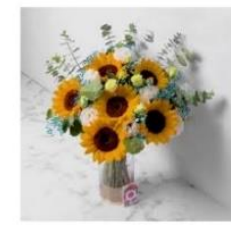

Specifications and price

5 per bundle, 15 yuan per bundle flower basket

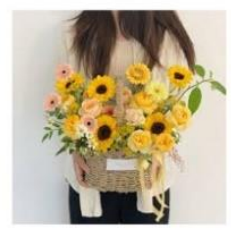

Figure 2 Flower resource display
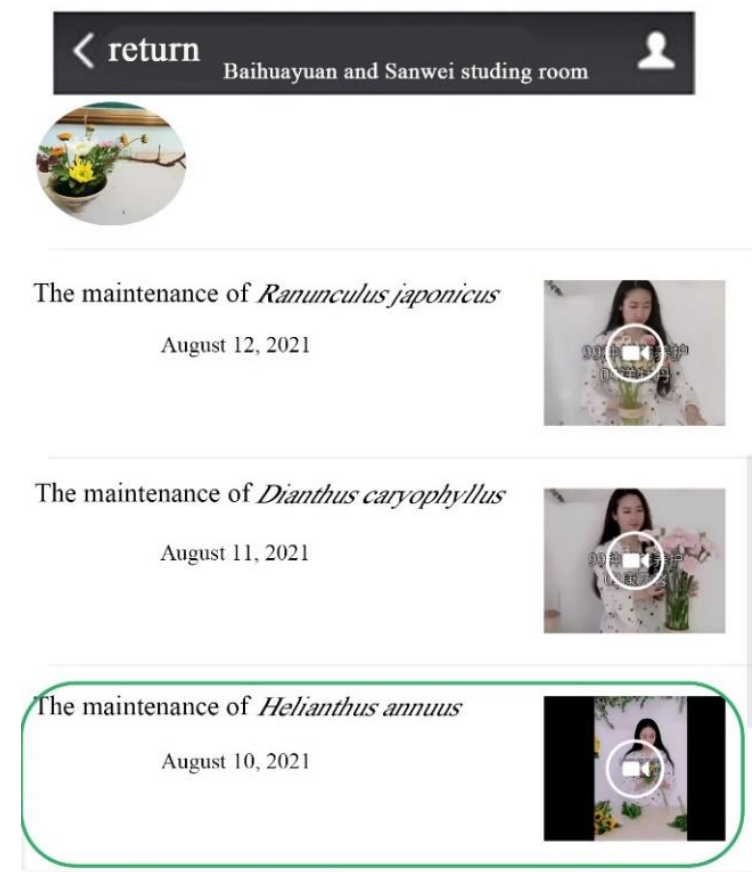

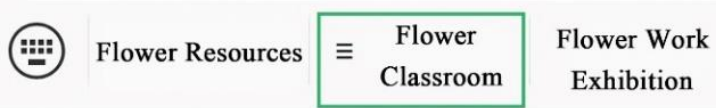

$\times$

The maintenance of Helianthus annuus

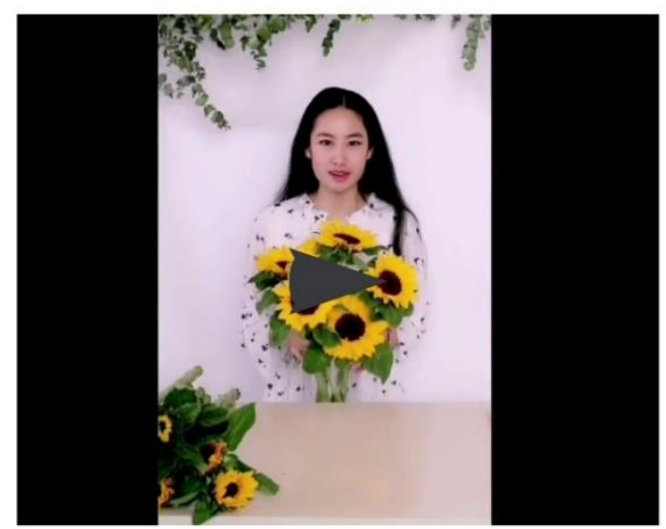

Sunflower flowers are sunny, bright, and have their own unique charm. Let us click on the video to learn how to conserve sunflowers and conserve our love of life.

more

Figure 3 Flower classroom display

\section{CONCLUSION}

Through training and education, you can use the WeChat platform to share corporate resources and solve the problem of inadequate resource identification and a single way to get learning resources for students. Second, ability-based goal-oriented education helped traditional education improve students' attention in flower arrangement classrooms, develop comprehensive abilities, and develop students' independent exploratory 
abilities. It means that you can solve the problem of not having it. Third, we will develop educational resources for the WeChat platform and use them to teach agriculture and forestry courses, visually display student learning outcomes and focus on student learning. This is very important for improving the quality of education in the classroom. Students can learn and integrate knowledge through a wealth of hands-on activities, improve their comprehensive application and innovation capabilities, and enhance their core competencies to meet their social development needs.

It also contributes to improving the adaptability of secondary profession students. There is a certain gap between the abilities of traditionally trained students and the practical skills required by the company. The content of the course lags behind the development of the times, and traditional teaching methods cannot completely improve student thinking and practical ability. However, the introduction of the OBE concept helps students acquire relevant resources with the help of corporate resources, clarify the main work of current career development trends, and plan important directions for future work. Therefore, in the process of learning and using the educational resource platform, we can better recognize our shortcomings and continually improve our knowledge system.

The WeChat platform, based on the OBE concept, supports the application of secondary vocational course education, shares corporate resources, clarifies what students learn and should do, and continuously improves their practical skills. It plays a positive role in improving student work adaptability and increasing talented employment competitiveness.

\section{AUTHORS' CONTRIBUTIONS}

Conceptualization: Duan Meiling proposed Ideas; formulation or evolution of overarching research goals and aims. Methodology: Duan Meiling, Zhong Yuqin and Min Wenrui, Work together to development or design of methodology; creation of models. Project administration: Huang Zijun and Lin Zhu responsenble for the mnagement and coordination responsibility for the research activity planning and execution. Funding acquisition: Hou Qinzheng Acquisite the financial support for the project leading to this publication.

\section{ACKNOWLEDGMENTS}

Thanks to Guandu Vocational Senior High School for providing a case teaching practice platform. At the same time, I would like to thank the laboratory teachers for their support and help.

\section{REFERENCES}

[1] Ministry of Education. Notification of the General
Bureau of the Ministry of Education regarding the issuance of "Points of Educational Informatization in 2017". Ministry of Education and Technology 2017 ) $2 . \quad$ [EB/OL].[2017-0203]http://www.moe.gov.cn/srcsite/A16/s3342/2017 02/t20170221_296857.html.

[2] State legislature. State legislature notice regarding the issuance of the National Vocational Education Reform Implementation Plan. Guofa [2019] No. Four [EB/OL].[2019-0213].http://www.gov.cn/zhengce/content/201902/13/content_5365341.htm.

[3] Liu Bing. The Applicantion Research of the Wechat Public Platform in Secondary Vocational Teaching Take the course "Computer Application Foundation" as an example[D]. He Bei University 2015 .

https://kns.cnki.net/KCMS/detail/detail.aspx?dbna $\mathrm{me}=\mathrm{CMFD} 201601 \&$ filename $=1015955746 . \mathrm{nh}$

[4] Spady, W. D. outcome-based Education: Critical issues and answers [J]. Arlington, VA: Ameri can Association of school Administrators.1994:1-10.

[5] Tam, Maureen. "Outcomes-based approach to quality assessment and curriculum improvement in higher education." Quality Assurance In Edition? (2014)22? (2): 158-168. ? DOI: 10.1108/QAE-09-2011-0059.

[6] Chandrama Acharya. Outcome-Based Education (OBE): A New Paradigm for Leaning[J]. CDTL ink,2003,Vo1.7,No.3.

[7] Li Zhiyi, Zhu Hong, Liu Zhijun, Guiding the Reform of Higher Engineering Education with Resultoriented Educational Ideas[J] Research in Higher Education of Engineering, 2014 (02) :29-34. DOI: CNKI:SUN:GDGJ.0.2014-02-004

[8] Su Ping, Li Manli, The Construction on Curriculum and Teaching in General Education in Tsinghua Case: An Approach of Outcome Based Education[J] Research in Higher Education of Engineering, 2018(02) :129-135. DOI : CNKI:SUN:GDGJ.0.2018-02-020

[9] Shi Xiaoqiu, design and Implementation of Course Teaching Based on the Concept of Outcome-based Education[J]. Research in Higher Education of Engineering, 2018(05):154-160. DOI : CNKI:SUN:GDGJ.0.2018-05-028

[10] IEJ Allen . Going the Distance: Online Education in the United States, 2011.[M]. Sloan Consortium. P.O. Box 1238, Newburyport, MA 01950. Tel: 781-583-7561; Fax: 888-898-6209; e-mail: info@sloanconsortium.org; Web site: http://sloanconsortium.org, 2011. 
[11] Outline of the National Medium and Long-term Education Reform and Development Plan (20102020) [J]. Chinese National Education, 2010, z1): 117.

[12] Bai Jing, Xie Youru, Li Wei, Wu Lihong, A Study on the Structural Model of Open Online Courses Resource Based on OBE Concept in "Internet+" Era[J]. China Educational Technology,2017(01):6470. DOI: $10.3969 /$ j.issn.1006-9860.2017.01.012

[13] Zhou Jingjing, Prospects of Using Modern Educational Technology to Improve Teaching Quality in Secondary Vocational Schools [J].Education Modernization, 2020, 7(5): 173-174. DOI:10.16541/j.cnki.2095-8420.2020.5.083

[14] GUO Wen-Tao, ZHAO Qing, WEN Wen-Jing, Construction and practice in micro mobile course resources of Medical Microbiology based on WeChat public platform[J]. Microbiology China, 2016, 43(4): 769-774. DOI: 10.13344/j.microbiol.china.150622

[15] ZHANG Da-Wei, LU Ke, ZOU Nan, Blended Teaching Practice of Agricultural Majors Organic Chemistry Experiment Course Assisted by WeChat Platform[J].CHINESE JOURNAL OF CHEMISTRY EDUCATION,2020, 41(12): 66-70. DOI: 10.13884/j. 1003-3807hxjy. 2019090122

[16] Wang Ping, Analysis of Support Functions and Design Principles of Mobile Learning Based on Wechat $[\mathrm{J}]$. JOURNAL OF DISTANCE EDUCATION, 2013,31(06):34-41. DOI : 10.3969/j.issn.1672-0008.2013.06.008

[17] PeÑ, I., aLó, and pez. "Mobile Technologies for Learning and Development (VII). Matthew Kam: Mobile Phones and Language Literacy in Rural Developing Regions.".

[18] QIU Bing-fa, MA Yan, LI Ming-yong, The Design of Mobile Learning Resources under the Support of the WeChat $[\mathrm{J}]$. Modern Educational Technology,2016,26(03):114-120. DOI : 10.3969/j.issn.1009-8097.2016.03.017 